\title{
Interdisciplinary Foundations for Environmental and Sustainability Ethics: An Introduction ${ }^{1}$
}

Małgorzata Dereniowska (Greqam, Aix-Marseille University; Marseille, France) Jason Matzke (University of Mary Washington; Fredericksburg, Virginia, United States)

\section{Introduction ${ }^{2}$}

Although environmental ethics is a young and dynamically developing field concerned with the human relationship to the non-human world, some core concerns and questions can be identified as having shaped its broadly pluralistic discourse. One main strand of thought has centered around the axiology of nature, in particular around the issue of the intrinsic value of nature, which includes questions of the ontological status of value, rights, and duties that might apply in different ways to a variety of things. The axiological questions are necessarily intertwined with those related to the meaning of nature and any related or contrasting classes or concepts, such as culture or civilization. A second set of questions relates to the status of the discipline itself, and the role philosophers might play in addressing the problems of global environmental change. Due to a perceived failure by some of environmentalism as a movement for collective action, various proposals have been raised suggesting a theoretical re-orientation of the discipline from one that focuses on overly abstract metaphysical and metaethical questions toward real-world problems and policy making. A third group of questions, which emerges from the ongoing decentralization of environmental philosophy, seeks to link

\footnotetext{
1 This work has been carried out thanks to the support of the $A^{*}$ MIDEX project (no ANR-11-IDEX-0001-02) funded by the "Investissements d'Avenir" French Government program, managed by the French National Research Agency (ANR).

2 We extend sincere thanks to the editors and staff of Ethics in Progress, especially Ewa Nowak for her continued support and assistance with this project.
} 
concerns about economic, social, and environmental inequalities and justice under a comprehensive theoretical framework, and seeks to address conflicts between environmental, social, and economic values and goals. By way of introducing the essays that make up this special issue of Ethics in Progress, we will comment on each of these, beginning with a discussion of the evolution and state of the discipline. A central theme in all of this is our belief that interdisciplinary efforts are crucial to the growth of environmental ethics and for applying it to questions of sustainability. This conviction is reflected as well in the essays collected herein.

The importance of considering ethically and politically laden questions from an interdisciplinary perspective 3 arises primarily due to the fact that environmental problems are so thoroughly integrated with other issues (most notably, economic and social matters) that solving them in isolation only raises or exacerbates problems elsewhere. For example, setting aside tillable land to provide protected habitat for threatened ground birds might raise the cost of food, a situation felt most sharply by those already economically marginalized. Or similarly, turning to hydroelectric power to curb carbon emissions can permanently destroy both aquatic systems and the means by which local people make a living. Whatever the answers, the various issues cannot be separated, and philosophy done with the aim of connecting to real-world problems must take this fact into account. By drawing on a wide array of disciplines and understandings, there is hope that we can better understand real-world issues that are grounded in multiple cultural, historical, and social conditionings present both in societal belief systems and scientific and analytic inquiry. A better awareness of the conditions that underlie and constitute discourses that are used in environmental debates is crucial for developing more meaningful and efficacious understandings and policies that are rooted in the past yet oriented toward the future. That a workable project of environmental ethicsone in which philosophers participate more fully in public discourse-must be grounded in a robust interdisciplinarity means that theorists must become better versed in fields outside of their discipline. At a minimum, this entails becoming more interdisciplinary as one engages in philosophy itself; but additionally, academic philosophers have increasingly moved beyond just acquainting themselves with the ideas of, say, ecological and economic theory, to becoming more fully engaged in direct conversations with practitioners in those fields and in policy making. They are co-writing articles and books,

\footnotetext{
3 In our use of the term "interdisciplinary," we do not mean to exclude the related notions of "multidisciplinarity" or "transdisciplinarity." All three notions, although slightly different in connotation, share in common the ideas of cooperation and understanding issues across traditional, disciplinary perspectives. Moreover, they imply each other in practice: multidisciplinarity is a precondition for interdisciplinary practice, as is the understanding of the social perception of science and the social conditioning of knowledge production.
} 
attending inter- and multi-disciplinary conferences, and are serving on policy boards and committees. The recognition that environmental ethics-like medical or legal ethics-must not operate in a vacuum or risk becoming selfisolating and ill-informed has emerged slowly, but surely, since the founding of the discipline.

\section{A Brief History of Environmental Ethics and its Role in Public Discourse}

Environmental ethics as a subfield of philosophy grew out of practical concerns about nonhuman nature in the context of the global ecological crisis and is not much more than four decades old. This is not to say earlier philosophers had ignored questions regarding the world we inhabit or how we are variously related to, part of, or situated in that world. However, efforts directed toward developing a new field of inquiry focused on expanding the moral community to include nonhuman nature ${ }^{4}$ and were intended to counter the traditional, individualistic, and narrow focus of classical ethical approaches that emphasized human character and actions only as these affected other people. Insofar as human beings were taken to have obligations toward the natural world, these were indirect, minimal, and grounded in direct duties only to each other (or to God) and not on any moral worth that plants, animals, or ecosystems might have in themselves. Contemporary environmental ethics, ${ }^{5}$ in contrast, is founded on the need to extend and take more seriously moral responsibility toward the nonhuman world, or to put it more broadly, on the inclusion of nonhuman nature in ethical reflection. Thus, the primary focus in the field, especially in its early decades, has been that of coming to better understand the moral status of, and our obligations to, the variety of nonhuman entities from individual plants and animals to wholes such as ecosystems and species. ${ }^{6}$

\footnotetext{
${ }^{4}$ The debate regarding the human-nature dichotomy is subject itself to much debate within the field of environmental philosophy. We use "nature" here to refer to the nonhuman world insofar as it can be usefully distinguished from the humanized, without implying any necessary dualism between nature and culture, the wild and civilization, and the like.

5 We use the terms "environmental philosophy" and "environmental ethics" interchangeably. Although the former might be taken favorably to include all philosophical inquiry related to nature, both ethical and otherwise, we marginally prefer the latter expression because it emphasizes that the ultimate end to work in the field is to inform our behavior and interactions with each other and the rest of the world, which is clearly a normative undertaking.

6 This does not mean that everyone working in the field believes that plants or ecosystems, for example, do in fact have moral standing independent of their usefulness to entities that do have moral standing, but rather that environmental philosophers have long been united in attempting to better understand such issues.
} 
That the discipline of environmental ethics, per se, is a fairly recent development does not deny the long tradition of writers outside of philosophy who contributed greatly to our understandings of nature and our proper relationship with it in ways that are more akin to what we find in contemporary environmental ethics than in the canonical philosophical tradition. In fact, many writers outside the mainstream of Western philosophy are regularly cited by today's environmental ethicists as their intellectual forebears, and represents one way in which the discipline has always been, at least minimally, interdisciplinary. In the American context, for example, Henry David Thoreau (1817-1862) expressed concern with the extent of humancaused change to his native southern New England, arguing that humans are "part and parcel" of the natural world and that only through intimate connection with the natural can one escape the conforming-and if unchecked, the degrading-effects of civilization (1993 [1862]). Following similarly the Romantic movement's reconceptualization of the human-nature relationship, John Muir (1838-1914) believed that in nature one could be closest to the divine. He explicitly rejected the common view that nature exists solely for human benefit, saying, "How narrowly we selfish, conceited creatures are in our sympathies! [H]ow blind to the rights of all the rest of creation!" (1991 [1916]). Ecologist and forester Aldo Leopold (1887-1948)-also strongly influencing contemporary environmental philosophy, especially through the work of J. Baird Callicott-argued for the protection of ecosystems and their constitutive parts in an ethical sense: he expressed a need to shift from mere economic valuations to internalizing a sense of duty to the natural world, which begins by recognizing that we are neither distinct from nor superior to those entities we too frequently treat as mere objects for our use (1987 [1949]). The sense of moral responsibility toward nature (a kind of ecological conscience) is grounded in an ecological and evolutionary perspective regarding the human place in the world. Although often less celebrated, there were important women thinkers too. In her influential 1962 book, Silent Spring, biologist Rachel Carson (1907-1964) wrote about the disastrous ecological effects of the insecticide DDT. Her work spurred wide public debate about society's blind faith in, and overreliance on, technology as the tool through which we interact with the world around us.

These works strongly influenced the environmental movement as it developed and gained strength in the later decades of the last century. As heralded as these authors have become, however, they represented nonetheless a minority tradition in society against which powerful interests have long pushed. In the early twentieth century, for example, arguments to dam a pristine California mountain valley, near to and resembling the famed Yosemite Valley, overcame Muir's public pleas for "higher" (and less destructive) aesthetic and spiritual uses of the valley than as a water tank for San Francisco (Muir 1988 [1912], 197). Some fifty years later, for her position on DDT Carson was 
attacked by powerful corporate leaders who disparaged her character and ability as a scientist. ${ }^{7}$ But by her time, public perception had begun to swing towards greater awareness of environmental problems and the failures of traditional ethics, the blind faith in technology, and a too often reckless public policy with regard to the natural world.

The works of each of these authors-as well as countless other authors, poets, artists, theologians, and scholars from around the world, wellknown and otherwise-are now taught with reverence in many grade schools through universities. More to our point here, the contemporary field of environmental ethics (especially as it has taken shape in the English-speaking world), and environmentalism more broadly, owes them an enormous debt. From them are drawn various possible alternatives to the common Western view that nature's value comes only from how it can be used to further immediate, and often merely economic, human interests, and that knowledge about the world is to further our control and effective use of it. To be sure, environmental ethicists disagree amongst themselves on key questions regarding the moral status and value of plants, animals, species, and ecosystems, but their willingness to challenge traditional views and to at least consider alternative models of the human-nature relationship (empirically, conceptually, and ethically) grows from the ideas of their intellectual and artistic predecessors - and, of course, from the growing cultural environmental awareness since the 1960s and 70s.

Regardless of how much theoretical disagreement exists, the men and women whose work created and sustains the discipline of environmental ethics exhibit a deep, shared concern for, and an intimate connection with, the natural world. As citizens of developed countries have become in recent decades more conscious of what our actions are doing to the natural world around us, academic philosophers wondered whether they could add to the growing conversations qua philosophers. Is there a role for academic philosophy in our efforts to address pressing ecological problems? What might philosophers contribute to our global efforts to find solutions to the environmental crisis? Despite the suspicion many felt from some of their traditionally-minded colleagues that "applied" philosophy was a watered down philosophy, people such as Holmes Rolston III, Richard Sylvan (Routley), Eugene Hargrove, and J. Baird Callicott (to name only a few) ultimately changed-along with those working in medical ethics, bioethics, animal liberation, and the like-how many in the field have come to view the role of philosophers. No longer would philosophy be limited to intellectual debates removed by several steps of abstraction from real-world concerns; philosophers could, and would, engage in

${ }^{7}$ For an excellent account of Carson's work and reception, see Linda Lear (1997). 
live cultural debates regarding ethics and policy.8 As James Rachels puts it: "Suddenly academic philosophers began to write about such matters as abortion, racial and sexual discrimination, civil disobedience, economic injustice, war, and even the treatment of nonhuman animals. It was a startling about-face for thinkers who, only a few years before, had agreed that 'A philosopher is not a parish priest or Universal Aunt or Citizens' Action Bureau"' $(2012,455)$. That is not to say that environmental and other more practically-oriented areas of investigation displaced other concerns in the discipline, or that philosophy historically has not strongly influenced our cultural beliefs and understandings - it clearly has. But the move by some in the discipline to connect with public issues has reminded many that philosophers could potentially make important contributions to pressing contemporary issues.

Nevertheless, we do not wish here to overstate the case. The discipline of environmental ethics remains focused largely on fairly abstract questionse.g., the meaning and proper attribution of intrinsic value to non-human entities and the social construction of wilderness-that are not often (in contrast to their more mundane and practical iterations) the direct concern of activists, policy makers, or citizens more generally. The role of the philosopher qua philosopher in society might continue to be of a fairly narrowly circumscribed sort in this regard. It is important to note that, as Włodzimierz Tyburski points out, one important role of the humanities is to supplement with an axio-normative element what we learn from environmental and economic science $(1990,9)$. Admittedly, a good deal of what philosophers do is rather abstract and the ability to engage with the arguments and positions advanced does require significant academic training. It is our view, however, that the more the discipline can be made accessible to non-philosophers, the more effective the discipline of philosophy can be in its participation in democratic discourse. This being said, it would be unreasonable to judge the value of philosophy based solely on the extent to which it has direct or immediate impact. After all, much of the published research in the sciences and social sciences, where practical application is more obviously likely and

8 This is not to say that everyone (or even most) in the larger discipline of philosophy engages in work that connects to real-world problems, or even embraces this as an ideal. Nonetheless, the discipline now clearly includes many who are committed to such a project. It is important to note also that even within the more narrow field of environmental ethics, there exists much debate about what engagement should involve. For example (as discussed below), some who identify as environmental pragmatists have argued that environmental philosophers continue to focus too much attention on esoteric and abstract issues - such as intrinsic value-at the cost of being able to influence positively public debate and policy. It would be more efficient, they argue, to look for areas of common concern and shared goals, using the power of philosophical analysis to provide better clarity of thought and direction (see for example the contributions to Light and Katz (1996)). 
expected, does not directly inform public debate or policy. But this is, as with philosophy, largely because the work of academic researchers a) depends upon whole collections of complex models, concepts, and methods, b) is often focused on rather narrow questions that become part of the accumulated understanding of a discipline that then does have more practical effects, and c) is not a final answer on a question, but one contribution that will then ideally go through a process of being challenged, modified, and sometimes even rejected. Often the very difficult, abstract questions about concepts and arguments involve further matters of complex metaphysical, epistemological, and ethical evaluation, which themselves require careful analytic analysis. Despite the abstract and complex nature of its work, however, philosophical inquiry does have an important and growing role to play in our global efforts to address environmental problems: philosophy excels at sifting through difficult, but important, concepts, models, and arguments that ultimately do have ramifications for public debate and policy.

\section{Axiology of Nature: The Problem of Intrinsic Value}

One example of environmental ethicists engaging with an issue intimately connected to contemporary environmentalism and social discourse is the continuing and decades-long debate on the concept of intrinsic value (sometimes also called "inherent value"). Axiological reflection-which seeks in this context to better understand and describe sources and holders of value in the natural world, as well as corresponding duties intended to protect or advance this value-has played a crucial role in the dynamic development of environmental ethics as a discipline from its beginnings. ${ }^{9}$ The concern over the intrinsic value of nature has become a predominant focus of emerging nonanthropocentric environmental ethics. As John O'Neill notes, the task of justifying and ascribing intrinsic value to nonhuman beings or entities (such as species or ecosystems) has become the Holy Grail for many environmental philosophers: "To hold an environmental ethics is to hold that non-human beings and states of affairs in the natural world have intrinsic value" $(1993,8)$. Many environmental philosophers will disagree with this claim due to doubts about the usefulness or even coherence of the concept, believing the focus and motives of the discipline to lie elsewhere. Nonetheless, a survey of the literature makes it clear that, for better or worse, the focus on intrinsic value has dominated the philosophical discussion since the beginning; even as environmental ethics continues to grow more complex and diverse.

\footnotetext{
${ }^{9}$ For more on the axiological foundations of environmental ethics, see for example the collection of essays in Zimmerman et al. (1993), Light and Rolston (2003), and Pojman and Pojman (2008).
} 
One reason for the focus on axiological issues is the conviction by many that the possession of intrinsic value has serious implications for decision making (both on the macro and micro levels): an entity that possesses intrinsic value, it is thought, must be taken into moral and political consideration by moral agents and policy makers in ways that go beyond purely humanoriented concerns. Although the specific language of "intrinsic value" is not necessarily a regular part of citizens', activists', or policy makers' lexica, the idea it captures is commonplace.

The standard account of intrinsic value refers to the value something possesses beyond its potential "instrumental value" (i.e., something's "use" or "extrinsic" value) to someone or something else. ${ }^{10}$ Often, conceptualizations of intrinsic value begin with how we think about ourselves and other peopleeach as valuable independently of his or her usefulness to others-and is extended then to cover other things: individual animals (e.g., our pets, livestock, and research animals) or plants, and perhaps collections or systems of things, such as ecosystems, species, or even landscapes. The claim that song birds, for instance, have value beyond their use value to us or other valuers seems to entail that we cannot act just however we wish but somehow must consider their well-being or interests. Questions immediately arise in public discourse when someone makes such a claim about song birds, previously unnoticed minnows, a lowly and rare cactus, and the like: Why should anyone agree that this or that organism should matter in my moral deliberations? What precisely is it about this cactus, or any cactus, that requires me to pay attention to how my actions, and public policy more generally, affect it? After all, it seems to have no identifiable interests in the same way that a person or other intelligent animal does. It is not conscious; it is not sentient: it does not care what happens to it. Further, even if it does have something like intrinsic value, it is not clear how to consider this fact alongside or in counter position to deeply felt human interests. Should they, for example, count for something like the same weight? It is not clear what that could even mean when the "interests" involved-if the word can be used coherently with regard to a cactus-seem of a quite different sort.

The notion of, or at least the use or emphasis on, intrinsic value has also been challenged by environmental pragmatists who argue that the focus on overly abstract metaphysical concerns, such as the ontological status of intrinsic

\footnotetext{
${ }^{10}$ It is worth noting, however, that the concept of intrinsic value goes well beyond its usual framing within the instrumental/intrinsic dichotomy. O'Neill, for example, distinguishes three basic meanings that the notion of intrinsic value can take: 1) "as a synonym for non-instrumental value," 2) as a synonym for non-referential value (in which an object holds value "in virtue of its 'intrinsic properties"'), and 3) as a "synonym for 'objective value'" $(2003,131-32)$. Lena Vilkka (2003) claims that there is a necessary pluralism to intrinsic value of nature due to different, irreducible levels of its application.
} 
value, has little appeal or conceptual meaning for the public, and as a result it contributes to the failure of academic environmental philosophy to affect global change (see Light \& Katz 1996). It is not clear, however, that unfamiliarity with the technical jargon of the philosopher prevents laypeople from having or using some basic notion of intrinsic value-or more precisely, some basic, sometimes conflicting, and even potentially inconsistent notion. The view that there is something more valuable in or about nonhuman entities than can be captured as units of utility or monetary notation to be traded against other quantifiable human interests is commonly held ( $0^{\prime} \mathrm{Neill}$ et al. 2008). Against attempts to quantify people's preferences on the single scale of monetary value, Andrew Brennon argues that "market prices do not seem to match people's normal perceptions of value," which reject the idea that one sort of value (instrumental, monetary, etc.) can be stretched to cover the whole variety of things we value $(2003,520)$. In fact, laypeople value nature (and other things too) in both instrumental and intrinsic ways (McShane 2009). In a study assessing the extent to which intrinsic value theories of nature are accepted and acknowledged outside of academic circles, Butler and Acott (2007) surveyed employees of twenty landowning organizations (both conservation and nonconservation groups) in England. Their results show that $80 \%$ of those surveyed embrace the idea that the environment possesses intrinsic value, although their conceptualizations and understanding of what intrinsic value is, or means, varies. Nevertheless, despite the plurality of views, two universal imperatives were apparent in the respondents' opinions: (1) “There ought to be some limit to the extent to which we may justifiably modify nature and we have a duty not to exceed that limit"; and (2) "We have a duty to have regard to nature's intrinsic value in our dealings with nature" (Butler \& Acott 2007, 455).

The discussion of intrinsic value by philosophers is not, then, removed from larger cultural understandings and debates; it is not a mere abstract philosophical notion. Further, the various views developed have been, expectedly, quite varied. As mentioned above, some thinkers have extended, in a fairly straightforward way, moral standing (the quality of being a necessary object of moral agents' attention) from the paradigmatic case of human beings to other intelligent, sentient, conscious beings. However, even here there is disagreement on the proper grounds of extension-sentience being widely seen as the defining mark, with more or less restrictive accounts also advanced-and how to then weigh competing interests or Kantian-like duties in cases of conflict.11 Laws against animal cruelty reflect general public

11 This particular strategy-called also moral extensionism-is most evident in patocentric and biocentric strands of environmental thought, and is objectionable to some due to its supposed anthropocentric implications. Wendy Donner (1996) argues, for example, that ascribing intrinsic values to nonhuman beings on the basis of criteria 
acceptance of the notion that humans are not the only beings who have value or standing. But it is more difficult, especially with plants and other nonsentient organisms, to extend standing to entities who share less with us than do, say, dogs and chimpanzees. Wholes, such as ecosystems and species, pose even more challenging questions since not only do they lack a literal center of consciousness or sentience (thus possessing no interests in the sense that is usually thought to be morally relevant), but worse, there are no clear or sharp boundaries-beyond, that is, how we might carve up the world in order to more easily pursue our scientific, aesthetic, or material interests-delineating one ecosystem or species from another. Further, that which benefits an ecosystem or species might work against the wellbeing of the particular individuals within it who are more clearly objects of moral duty.

Some philosophers, such a Kenneth Goodpaster, have argued that it does in fact make sense to attribute interests of a sort, and hence moral standing (or value), to things such as plants since they need water and sunlight (2008). Holmes Rolston III argues that ecosystems and the biosphere itself have intrinsic value (2008). Others have objected that it is not possible to extend standing or intrinsic value to things that are not sentient valuers themselves. Obligations to things like plants or ecosystems must come, J. Baird Callicott argues, from the perspectives of sentient valuers. Things like plants and ecosystems have intrinsic or inherent value only in the sense that we value them in ways not reducible to mere use-value; the value might reside in a plant, but it originates from us (Callicott 1989, 133).

It might turn out that although the notions of interests and moral standing are coherent and useful in our moral theory and practice, intrinsic value (even in reference to people) is either incoherent or, at least, unnecessary. ${ }^{12}$ One approach is to note that if it is moral standing that we are ultimately concerned to identify in the entities and wholes around us, we could jettison the ambiguous and unclear-the mysterious-notion of intrinsic value. It is ontologically simpler to identify more empirically verifiable traits or relational qualities of things that make it necessary that we moral agents pay attention to their wellbeing when acting. There might be a variety of such traits or qualities, but we can, without losing important substantive elements, skip the question of whether their possession gives an entity moral standing directly or does so by giving the entity some sort of value that then entails standing. It is not our intent to answer this question, but to note instead that philosophers continue to do what they do best-careful conceptual and argumentative

that we happen to consider to be important in us is far from the naturalistic ambitions of the field to find a non-arbitrary source for moral standing.

12 Bryan Norton (2003) and Eugene Hargrove (2003) have both written about the relationship between anthropocentrism and nonanthropocentrism, on the one hand, and various types of value, on the other. 
analysis-offering a variety of approaches meant to capture the now widespread cultural conviction that nonhuman entities (individuals and wholes) have value that is not reducible to anthropocentric interests.

\section{From Environmental Ethics to Sustainability}

The shift in recent years to the notion of sustainability as providing the governing conceptual framework for local, national, and international policy making that integrates social, economic, and environmental dimensions is a clear example of the need for interdisciplinary cooperation; it is also an example of how environmental philosophy has broadened its scope beyond the axiological. The concept of sustainability is anything but settled (Söderbaum 2008), though several fundamental elements appear in most accounts: environmental protection, social justice, intra- and intergenerational distributive justice, and democratic decision making. Such a broad concept, with possible diverging programs and goals, makes it all the more important to both arrive at a coherent and workable concept (or set of concepts) and to have it grow out of a more-or-less consistent collection of understandings: philosophical, economic, social, democratic, and environmental. At the very least, sustainability discourse represents an attempt to create a platform in which the tensions between different values and visions of the world are made visible, and hence subject to negotiation about what kind of future we collectively want (Robinson 2004). One of the ways this might occur is for philosophers to help clarify the various structures, concepts, and schools of thought related to ethics and decision making. This would involve developing a more comprehensive and workable model of pluralism, where this eschews the deep skepticism and corresponding radical relativism of postmodern epistemologies while allowing for a certain amount of irreducible, but reasonable, disagreement that seems inevitable as we seek definitions, goals, and policies for a global sustainable future.

From the perspective of environmental ethics, sustainability discourse represents both a shift in thinking and a promising way forward-a way to bring together a whole host of concerns that have too long been talked about in isolation from one another. Most obviously, sustainability has the potential to overcome a rather persistent dichotomy in environmental thinkingconservation vs. preservation-both sides of which aimed to push back against unfettered development. The dispute between John Muir and his once close friend, forester Gifford Pinchot (1865-1946), illustrates the difference between these two approaches. Pinchot argued on utilitarian grounds that public ownership and management of forests protected natural resources for longterm use while also preventing a select few from reaping the benefits that should belong to the greater public. By keeping forests (and later grasslands, etc.) under common, public control and management, citizens could more 
wisely use their natural resources. Muir, in contrast, argued sharply against some of the uses proposed by Pinchot, such as grazing sheep or building dams in public parks or forests. He cited a need to protect nature not for human use, but from human use, or at least from the sort of use that would radically alter a natural place. These competing approaches have together provided a framework within which several other competing views have been (though not by conceptual necessity) arranged. The intrinsic vs. instrumental arguments, for example, could be lined up conveniently under preservation and conservation, respectively. Similarly, the view that human knowledge is superior to the unconscious unfoldings of wild nature-that we know best how nature ought to work-matches up well with the conviction that rather than simply letting natural events occur as they will, we should train experts to manage wild areas. Although there is an apparent complementarity between conservation and preservation - the former relating to the wise use of the environment; the latter focusing on preserving wild nature from certain kinds of human use-the results of their application are often different, as illustrated in the Muir/Pinchot disagreement. However, if we look more closely at the polarized dichotomy between nature and culture, we see that it is difficult to draw a sharp line between the natural world (taken to be worthy of protection) and the inhabited, humanized environment, seen as the source only of problems. ${ }^{13}$ The notion of pristine nature, as unspoiled by human intervention, has been roundly criticized, most obviously because most areas in the world have been altered more or less by human influences. ${ }^{14}$

The promise of the sustainability concept lies in the inclusion of ecological, social, and economic dimensions under one framework, and in its ability to blend global concerns with the local. Nevertheless, sustainability discourse embodies similar inherent tensions-such as between the intrinsic and instrumental, or between anthropocentrism and ecocentrism-that have troubled environmental philosophy since its beginnings. This recognition points to the importance of the framing (and consequently, of the schemes organizing human thought) of environmental matters.

Recent growth of a new subfield, climate ethics, makes even clearer the double bind at the intersection of ethics and public deliberation. Philosopher Donald Brown distinguishes two dimensions of the ethical challenge of climate change: the lack of ethical scrutiny in the realm of decision making and the inability of ethicists to seriously engage with direct problems arising from

13 Historically, protection efforts have been focused on the most scenic and undeveloped areas, with the less sublime and semi-natural spaces being thought unimportant to preserve due to their already "degraded" status.

${ }^{14}$ For a more detailed discussion of the social construction of wilderness, see Callicott \& Nelson (1998) and Cronon (1996). 
political contexts such as the limits of economic arguments informing policy measures regarding climate change or distributive justice (Brown 2013, 235).

One of the reasons for the ethical malaise is the fact that environmental philosophers have tended to conduct their debates within their own narrow academic field. Consequently, the growing body of the ethical literature had little impact on informing policy making (Brown 2013, 237). More recently, however, work on the issue has taken a practical, applied turn, founded on a theoretical reorientation from analyzing abstract questions of what perfect justice requires and looking for foundations for human duties toward the environment, to working to identify ethical issues inherent in policy debates. Environmental ethics can contribute to improving policy making by providing greater conceptual clarity regarding justice, what the notion of moral responsibility includes, and how its components (e.g., intergenerational concerns) can be reconciled with the exercise of freedom in democratic societies. Such work, Brown points out, "help[s] policy makers and citizens understand the limits of instrumental rationality when science and economics are used to define environmental policy, because instrumental arguments are at the center of public policy disputes about environmental issues" $(2013,238)$. Consequently, ethical consideration must not rely only on the question of what ethics requires in the abstract; after all, different ethical theories may lead to different, or even conflicting, positions on particular matters. In other words, ethics can be made more relevant by focusing on setting minimal standards that policy proposals must meet in order to be considered legitimate options. Despite the fact that the disagreement about particular cases will likely remain, we can at least begin by identifying overlapping consensus on unsubstantiated and ethically dubious positions. The demand for a practical approach is particularly evident in the context of the limits of corrective justice to account for existing inequalities and the distribution of environmental burdens. From the perspective of environmental ethics, the question of the adequacy of philosophical theories and concepts when applied to urgent global problems like climate change is, thus, not merely a question of theoretical reorientation, but also a question of how to use them in practice. On this view, moral practice entails the ability to make reasonable judgments. Since climate change poses a complex and multidimensional problem, a shift in emphasis toward proper ethical reflection on the problem seems to be a more promising approach than is theorizing in the abstract. Nevertheless, we maintain, theory building remains an important task as it plays a role in the articulation and evaluation of social values and beliefs.

\section{The Contributions to this Special Issue}

Environmental ethicists have greatly expanded the discipline's scope, the role of academic philosophers in public discourse, and the extent to which 
philosophers engage with those beyond the traditional confines of the discipline. The collection of essays in this volume illustrate the range of perspectives and approaches being brought to bear on the complex environmental and sustainability issues we now face. This volume includes work that illustrates this fact while also illuminating our understandings of particular problems, such as overpopulation and consumption, responsibility for future generations, and the resolution of value conflict. It represents authors from Europe and North America-five countries in total-and the disciplines of history, aesthetics, sociology, and philosophy.

When environmental philosophers talk of how the field is shifting in ways that better relate abstract theory with real-world considerations, they are often talking about how their work connects to issues of policy formation. The discipline has certainly entered more explicitly and fully into debates about wilderness and resource management, restoration of damaged lands, and, most obviously, sustainability and climate policy. The essay by sociologist Paul Joosse reminds us, however, that engaging with the world of action can take us as well into thinking about the aims, justifications, and results of activists who may or may not be on board with much of what generally counts as defendable philosophical positions. As he points out in "Antiglobalization and Radical Environmentalism: An Exchange on Ethical Grounds," a number of recent events-from the further commodification of our lives to the further degradation of both the environment and workable ways to enact positive change-have converged to create a new sort of "radical environmentalism." In contrast to slightly older radical groups, such as Earth First!, these newer activists-of which Earth Liberation Front (ELF) is Joosse's primary exampleeschew the rhetoric and aims of a narrow environmentalism in favor of a transnational anti-globalism and anti-capitalism. They are self-proclaimed "revolutionaries" challenging the institutions of neoliberalism.

One of the worries about groups such as ELF is their willingness to use strategies and tactics of fear. They have used arson, for example, to destroy a 206-unit apartment building under construction in San Diego, California. Of the many important ethical questions that this raises, Joosse chooses to evaluate the group based on three objections raised commonly against the larger antiglobalization movement, of which, he argues persuasively, ELF is a part. The criticisms he deals with all involve essentially the issue of effectiveness. This concern is elevated in the sense that the anti-globalization movement-and by implication, ELF as a part-is not only ineffective, but actually counterproductive to its aims. More specifically, it is so by dint of the fact that it is preoccupied with the tactics of property destruction and mega-protest (e.g., against the WTO, World Bank, and IMF), and that it ignores national politics in favor of the transnational. Joosse argues that ELF's willingness to engage in property destruction allows government and business to define environmentalists of all sorts as dangerous radicals, even "eco-terrorists." Media 
similarly frames things, especially following the events of September 11, 2001. As Joosse suggests, ELF allows, then, powerful champions of neoliberal globalization to link the so-called war on terror with environmentalism.

It is instructive to note not just what Joosse is doing, but what he is not. First, he is not criticizing the underlying philosophical positions of the antiglobalization or capitalism movement. Second, he is not questioning the tactics of radical groups from the perspective of ethics, per se, but rather in terms of effectiveness. These are quite different analytic approaches since ethics is seemingly about more than mere effectiveness; the work Joosse has done, however, is of significance to anyone wanting to mount a more fully ethical evaluation of the radical environmental movement. Regardless of one's position on particular ethical theories, most would at least care about whether the worrisome tactical actions (if we are to sustain a general moral proscription against violence) result in positive ends. Finally, Joosse is very careful to distance ELF from environmentalism more generally, and even from other socalled radical groups. The account that he puts forth of the genesis of ELF posits the group as an spinoff of Earth First!, but as he notes, this does not mean they ultimately share many things in common. Earth First!, for example, is (or perhaps more accurately, was) generally focused on narrow concerns such as wilderness protection, worked largely within a framework of national or international politics, and has pulled back from even more moderate forms of eco-sabotage such as tree-spiking. Even insofar as some in its membership came to identify with more anarchistic views and saw environmental concerns as only one set within a larger constellation of concerns (e.g., social justice, animal rights, and antiwar), Earth First! cannot be accurately said to be a part of the current anti-globalization movement in the way ELF is.

The essay by philosopher John Mariana, "Overconsumption, Procreation, and Morality," is about a whole lot more than is at first apparent. Narrowly, it amounts to a critical appraisal of Thomas Young's argumentaimed at typical "mainstream environmentalists" - that procreation and overconsumption are ethically equivalent. Mariana contends that Young's argument could be greatly improved, but that ultimately even then it cannot be sustained with the limited theoretical resources at hand More widely, the essay challenges us to think more carefully about how ethics-or philosophy more generally-might better inform our beliefs about population growth vis-à-vis consumption and limited resources.

In short, Young argues, as outlined by Mariana, that the effects of having children beyond replacement numbers has negative effects equivalent to those of overconsumption. He defines overconsumption as consuming beyond the current American average. Following an interesting discussion of the difficulties of defining overconsumption, Mariana spends much of his article evaluating Young's replies to four criticisms that point to dissimilarities between procreation and overconsumption. The four objections are that 
procreation a) is the less selfish of the two, b) is a better source of happiness, c) involves a fundamental right absent in overconsumption, and d) creates beings of inherent worth. Young's defense in light of these objections involves, according to Mariana, claims difficult to maintain consistently, such as: a) many people have children for selfish reasons, thus motivations should not count in our evaluation of the two behaviors, b) utilitarianism cannot be defended anyway, and c) nonetheless we should be thinking in terms of outcomes. Mariana acknowledges Young's desire to not embrace any particular theory as viable, but notes that if he wants to evaluate the behaviors according to their effects, we do need some way of making the comparison.

Mariana provides a possible defense for Young: we could acknowledge that people tend to see higher good coming from bringing children into the world than they do in increasing their consumption beyond that of an average American (wherever the line of overconsumption finally gets drawn), and then note, however, that no value exists independently of others. In this way, one can see that even if having children beyond the number needed for maintaining a steady population adds important value, this eventually leads us to the situation where resources are so taxed as to lessen the quality of life for everyone. Mariana points out, however, that even this stronger case for the equivalence of procreation and overconsumption needs philosophical support. This support is lacking, as he demonstrates in his discussion of what it might mean to harm someone not yet in existence. Mariana suggests further that an adequate account of the ethics of procreation must take into account our character. Is one selfish for wanting children? For not wanting children? Finding no clear way of answering these questions, Mariana closes by noting that we simply do not have the requisite theory to make evaluations across (real and potential) generations when we are unable to properly estimate the value and costs of procreation relative to consumption and quality of life. But Young's refusal to embrace the notion of intrinsic value for individuals makes it difficult to know how to make sense of human (and other) interests. Thus, Young's account ultimately fails; we are in need of continued work.

Katia Vladimirova picks up on one of the difficulties identified by Mariana. In "The Pure Intergenerational Problem and the UNESCO Decade of Education for Sustainable Development," she raises the question of whether we can develop an adequate account of future generations in moral thinking related to problems posed by climate change. She begins with reference to the metaphor of the perfect moral storm, introduced by Stephen Gardiner to illustrate that temporal, spatial, and institutional attributes of climate change constitute a setting that encourages moral corruption, indifference, and the incapacity to undertake collective action. ${ }^{15}$ Gardiner's use of the metaphor helps

15 Inspiration for Gardiner (2010) for the development of the metaphor of the perfect moral storm comes from Sebastian Junger's 1999 novel, The Perfect Storm: A True 
identify the peculiar features and normative challenges that climate change poses; in particular, it highlights the fact that the elements constitutive of the climate change problem in the context of decision making render it impossible to address the problem's symptoms without questioning the underlying normative and epistemological questions of climate science, policy making, and the general functionings of society (Gardiner 2010). The intergenerational element adds complexity to Gardiner's perfect moral storm, since the temporal fragmentation of agency makes it difficult for agents to unify and act as if they were a single agent. Vladimirova considers an idealized version of the intergenerational problem, the so-called Pure Intergenerational Problem (PIP), 16 as a situation in which standard institutional solutions do not work. She proposes that instead of looking for an adequate institutional solution, we can try to change the very context-the rules of the game, so to speak-by altering the dynamics between individualism and collectivism (which in this case includes not only existing but also future generations). For the Prisoner Dilemma, the logic of conflict resolution rests on the assumption that choice is fully rational. This assumption, combined with a focus on self-interest as defining the human condition, renders any choice in favor of collective benefit impossible. One way to change the institutional context is to promote a broad value shift by emphasizing the moral considerability of future generations. Such a move does not imply, however, that the interests of future generations will, or even should, outweigh the interests of present generations. Rather, the point is that we should include concern for future generations as a universal standard in ethical reasoning and decision making. This new way of thinking, Vladimirova points out, must be founded on a new, universally shared value system that directly relates current to future people.

The requisite set of values can be found within the 2002 educational agenda of the United Nations-the Decade of Education for Sustainable Development (DESD) - which aims at promoting values central to sustainable development and inducing broader behavioral and social change. ${ }^{17}$

Story of Men Against the Sea, in which the main character, a fisherman, finds himself caught in the convergence of three bad storms that together create the "perfect storm." ${ }^{16} \mathrm{PIP}$ is a variation of the Prisoner Dilemma in which generations do not overlap.

17 The question of value universalism is itself a challenge for environmental ethicists trying to develop a context-sensitive program that accounts for historical and cultural factors that shape socio-economic conditions of particular places. Such programs necessarily rely on inducing collective action, which cannot be done by coercion or in the top-down fashion too often evident in global environmental policy trends. Recourse to universalism may pose a risk of absolutism, which is unacceptable from a social justice perspective. However, there is growing agreement that issues of environmental and climate justice cannot be properly addressed in a relativistic framework of a Westphalian world (that is, a multipolar world of sovereign nations-states protected against external influences), since moral relativism would undercut international solidarity in fighting against global ecological problems such as climate change. Thus, 
Mainstreaming values related to the environment and future generations can be achieved via diverse means, of which education is one of the most recognized. Since UNESCO is an important institution whose role is to foster educational agendas, it is instructive to look at its DESD in order to articulate the set of values that ought to play a crucial role in educating for a sustainable world These clearly articulated values, Vladimirova argues, can be seen as a part of the solution to the PIP problem that goes beyond both technical and structural fixes. It does so by linking the present with future-oriented concerns about the environment and people, thereby stretching the scope of moral consideration to include future generations and allowing a shift in the balance of trade-offs between present and future generations away from the current exclusive favoring of the former. However, DESD and the values it promotes have been subjected to the criticism that it is just another modernization project supported by a neoliberal economic and political ideology. In addition, the necessity of nontrivial trade-offs between sustainability and development makes the project susceptible to skepticism expressed in many academic circles. Nevertheless, we would add here that it is important to note that a set of values for sustainability will likely not be coherent in the sense that all moral dilemmas related to environmental problems will be resolvable without some compromise on what is valued. In other words, possible value conflict should not be understated, and the question of how to deal with it and what trade-offs are morally justified remains an important challenge as we address climate change. Consequently, an adequate response to the perfect moral storm must be founded on a cluster of factors that facilitates collective action, including not only institutional settings, but also beliefs and value frameworks within which institutions operate.

In "Building within space: Thoughts towards an Environmental Ethics," historian Troy Paddock reflects on the origins and development of the anthropocentric, instrumentalist view of nature deeply embedded in the Western system of values. Since the sustainability-oriented project of environmental ethics needs to be founded upon a proper sensitivity to the link between our actions and their impacts on the non-human world, Paddock focuses on grasping the nature of human action and the experience of environment as space in which humans act. He draws on insights from architecture since it is fundamentally about the organization of space. Analogically, the instrumental, anthropocentric view of nature is precisely about the organization and rearrangement of space. Architecture is illustrative of the characteristics of human action that shape the relationship between human beings and their environment, as this has evolved in modern culture,

there is an urgent need to develop a global, yet context-sensitive normative framework that would set standards for ethical scrutiny and allow for joint considerations and negotiations on matters of environmental and climate policy. 
which is characterized by an asymmetry that has led to the objectification of the environment. In order to better understand the nature of this asymmetry, Paddock draws from Bernard Tschumi, who claims that architecture is impossible without action, events, and program. Consequently, "there is no architecture without violence" (Paddock 2014, 83). By extension, Paddock continues, an asymmetry exists in the relationship between human beings and the environment, characterized by a kind of violence that is inherent in the confrontation of the logic of objects and of people.

Paddock follows Tshumi's recognition of the inseparability of space and action, where the interplay between two orders is a function of our surroundings as well as of actions and events taking place within those surroundings. He proposes that the project of environmental ethics is basically about balancing these two orders. A symmetrical relationship exists between them, where the relation of dominance (and thus violence) is minimized or possibly eradicated: "symmetry is connected to ethical action, and by extension that symmetry is required for environmental conservation" (Paddock 2014, 84). To illustrate the point, Paddock analyses the example of the Mosel River in order to show how the relationship of violence in the human-nature relationship can be constructively transformed by changing the way we think of the environment.

The taming of rivers such as the Mosel can be seen as an illustration of human dominion over nature, where nature objectified is something to conquer. However, when the Mosel River is considered as a space in which our actions take place, without being objectified, it is possible to practice ecological restoration that goes beyond techno-fixes. Such practice is grounded in a sense of interconnection between human agency and two orders of needsinstrumental and generative-which come into play via inter-action with the environment. On this account, an "ethically wise person" acquires a debt via actions that serve both orders of needs. The idea of harmony with nature is, however, not self-sustaining. It requires a conscious effort directed to maintaining it, which is a corner stone of symmetrical action. The tension at the heart of our understanding of what nature is, and how to best frame our relationship with it, is grasped by the recognition of the inherent tensions in the human-nature relationship: "A disconnection with nature is at the heart of this sense of nostalgia and loss" (Paddock 2014, 88).

Change in values and beliefs must be epistemologically well grounded. Further, following John Scott's Aristotelian account of two kinds of needs and needs ordering, Paddock's work makes the case for a broader framework for analyzing policy questions regarding issues such as climate change. After all, these questions cannot be considered merely as a matter of "pure" scientific fact, but rather they involve questions of value. Reductionism in policy analysis is yet another reiteration of the epistemological trap, described by Paddock via reference to Heideggerian modern transformation of technology and its 
relationship to nature. Actor-Network Theory is presented as an opening up of the possibility of restoring the symmetrical relationship between the human and nonhuman worlds.

Another perspective is offered by Mateusz Salwa in "Historic Gardens as Places of Conflicting Values." Salwa explores the issue of natural gardens as an example of human creation taking control of natural forces. Nature in this form can be contrasted and juxtaposed with wild nature, or wilderness. In some sense, gardens can be seen to be more like a human monument than like nature; for example, we tend to view gardens through the lens of nostalgia: "Gardens are always human-made; they are places where the natural environment is transformed according to a person's aesthetic experience and expectations" (Salwa 2014, 97). Salwa explores the inevitable conflict of values regarding humanized nature, arguing that in order to arrive at clear answers and actions related to ecological restoration, it is important to make transparent the beliefs and values that underlie our thinking. This inevitably includes the question of intrinsic value. Using the Krasinski Garden in Warsaw as his case study, Salwa argues that abstract philosophical questions lie at the core of disagreements regarding garden restoration and management. For example, to what extent are the nonhuman elements of a garden, such as plantings, "natural"? To what extent are human interventions in an ecosystem's dynamics justified? What kind of values are attached to a garden? Is a garden merely a stage for human activity? Drawing on the history of art, and in particular on Alois Riegl's work on monuments, Salwa crosses disciplinary boundaries to undercover patterns of value conflict and the challenges faced in the maintenance of monuments. These patterns can be applied not only to monuments, but also to so-called natural monuments, including, insofar as they may be so conceptualized, gardens as humanly created living works of art.

Gardens such as the Krasinski Garden are often thought of as "historic gardens," and as such are defined as "timeless" in the sense that each garden has an original shape that ought to be preserved. The most important values of a historic garden are artistic, wherein all the nonhuman elements (e.g., plants and animals) are subsumed under the "timeless" artistic structure. A competing perspective sees gardens as "living areas." The tension between the two views illustrates well that our understanding and ways of maintaining gardens can be quite diverse. At the heart of the conflict in the public debate about how to best restore the Krasinski Garden, Salwa notes, lies a clash between the art-historical and the social-ecological perspectives. His applied study and conclusions reflect some of the deep philosophical issues related to ecological restoration in general, such as are found in Robert Elliot's book, Faking Nature: The Ethics of Environmental Restoration (1997). Is a garden a purely cultural phenomenon? A monument? Or is it an ecosystem? Should the historical or the ecological prevail? 
Such stark choices are not, Salwa points out, mutually exclusive, and the dichotomies involved need not be treated antagonistically. This issue lies at the core of any conflict resolution. In other words, the fact that we cannot fully escape the nature/culture, intrinsic/instrumental value, subject/object, etc., dichotomies does not necessarily imply dualism. Salwa's claim is consistent with that of Val Plumwood, who points out that dichotomy, in its basic sense, means drawing differences, which is an essential feature of human thinking (1993). Dualism, however, includes also hierarchical relationships, or arrangements, of dominance and even violence; this is not an inherent feature of human thinking. Or, using terminology provided by Paddock, the human/nature and other dualisms are forms of an asymmetrical relationship between subject and object. In asymmetrical relationships the category of difference is overlooked, objectified, and subsumed wrongly under mere instrumental goals. The capacity of dealing constructively with conflicts of values requires that difference not be treated antagonistically. The relationship might then become more symmetrical.

The problem of attitude toward difference (that is, the Other, whether human or environmental) is investigated in more depth from an ethical perspective by Krystyna Najder-Stefaniak in "Value of an encounter from an ethical perspective." The environment is a physical site, but also, she argues, something imagined, perceived, and experienced through schemes of reasoning and valuing. Such space is an intermediate between the spheres of the descriptive, the prescriptive, and praxis. It can be altered by us in two ways: by changing the external environment and by developing or destroying the human ability to perceive and understand the environment. Thus, "the shape of the space depends on human capabilities and cognitive skills to a great extent" (Najder-Stefaniak 2014, 120). Such an account is consistent with the normative recognition that we need to think differently about nature while acknowledging the pluralism of values and attitudes that must be accommodated in decision making (both on the individual and institutional levels) regarding the spaces in which we live. The twofold interpretation of the environment, when applied to environmental ethics, shifts the emphasis of the discussion from fragmented and separated dimensions within ethics and between ethics, to practice oriented toward what ethical reflection is supposed to be at its roots: not just rules and principles of conduct, but a strategy for living that advances the development of the art of being. According to Najder-Stefaniak, one of the most important abilities in the art of living is the ability to realize encounters. The condition that makes an encounter possible is the existence of difference. However, pluralism implies many possibilities for how the encounter with difference will be contravened and what will result. The category of difference that justifies pluralism contains nothing in itself that would imply an outcome with no ambiguity, as in, for example, the rejection of some universally held belief. Rather, both the process and the results of an encounter with difference 
depend upon how difference is approached, or, to put it more directly, on the schemes of thinking and reasoning with which we are engaged. NajderStefaniak distinguishes four types of schemes that organize our thinking and which determine modes of encounter with difference: antagonistic thinking (reflected in an either-or approach, resulting in the rejection of difference), complementary thinking (embodied in mediating strategies of dealing with paradox), dialectical thinking (allowing one to transcend the level of thesis and antithesis to discover their synthesis), and synergistic thinking. The latter scheme of reasoning is best suited to facilitate meta-reflection and understanding the conditions of difference and how it is constitutive also of ourselves. It results in creativity and enables us to go beyond identity borders without these being threatened. This is the condition for an ethical encounter in which difference enriches the participating parties and inspires the search for truth.

The capacity to realize different types of encounters illuminates the practical potential of the ecosystem metaphor insofar as it captures an alternative relationship to that provided by modern dualism between subjects and objects. Such a move allows us to conduct a dialogue of an I-Thou sort (in a Buberian sense). Here, the outcome of the encounter with difference becomes complimentary or synergistic by means of dialogue as an ethical relation. Such a relationship takes place in an open system between two beings in dynamic interaction that are constitutive of the whole. As Najder-Stefaniak argues, "Were we to see relationships in keeping with the ecosystem paradigm, causality would no longer be linear and one-sided; we would become capable of finding new aspects of human interdependencies and of understanding our relationship with, and links to, the environment, conversely to the modern paradigm" (Najder-Stefaniak 2014, 119). Consequently, the scope and meaning of moral responsibility can be extended to include also the fact that our actions, as well as the way we construct the environment, influence the modalities of "gestalt." Such a perspective allows us to transcend the antagonistic patterns pervasively framing the nature-culture relationship and discourse about it.

\section{Conclusion}

The task of presenting the developments, relevance, and challenges of the discipline of environmental ethics is not an easy one. The plurality of environmental discourses and the wide array of perspectives on environmental problems makes it necessary to select some elements of the discussion at the expense of others. Nevertheless, the goal of this collection of essays is not to provide anything resembling a complete picture of the state of the discipline, but to provide a sample of current work illustrating the ethical and meta-ethical questions and tensions that have pervaded environmental ethics since its origins. These tensions can be illustrated by James Proctor's metaphor of the 
solid rock and shifting sands (Proctor 2001). According to him, environmental ethics is dealing with inevitable tension between subject and object on an epistemological level, and between universalism and particularism on the ontological level. Although the rise of environmental philosophy has been marked by naturalistic attempts to provide objective grounds for moral obligations toward the non-human world, the fact of the social situatedness of knowledge and valuing may be seen, at least to some environmental realists, as undercutting the promise of inducing global social change. Nevertheless, the challenge lies in the way we think about the multidimensional aspects of the ecological crisis. If approached non-antagonistically, we can arrive at an environmental ethics aspiring to universality (yet avoiding absolutism) while being explicitly context-sensitive. In other words, the project of practical environmental ethics is, at least in some ways, that of creating a new ethics (following Richard Sylvan's earlier call (2003)) in a way that does not fully break with tradition but certainly goes beyond the received notions involved in our thinking about non-human nature and morality itself. The qualitatively new characteristics of the global challenges we face today necessarily lead to a rethinking of what ethics is, what it requires, and how we understand and act in the world.

\section{Literature}

Brennon, A. 2003. "Environmental Awareness and Liberal Education". In Light, A. \& Rolston III, H. (Eds.), Environmental Ethics: An Anthology. Malden, Massachusetts: Blackwell.

Brown, D. 2013. Climate Change Ethics. Navigating the Perfect Moral Storm. London: Earthscann (Routledge).

Butler, W.F. \& T.G. Acott. 2007. "An Inquiry Concerning the Acceptance of Intrinsic Value Theories of Nature". Environmental Values 12 (2): 149168.

Carson, R. 1994 [1962]. Silent Spring. Boston: Houghton Mifflin.

Callicott, J.B. 1989. "On the Intrinsic Value of Nonhuman Species". In In Defense of the Land Ethic: Essays in Environmental Philosophy. Albany: State University of New York Press: 129-55.

Callicott, J.B. \& M. Nelson (Eds.). 1998. The Great New Wilderness Debate. Athens: The University of Georgia Press.

Cronon, W. 1996. "The Trouble with Wilderness; or, Getting Back to the Wrong Nature". In Uncommon Ground: Rethinking the Human Place in Nature. New York: W.W. Norton and Company: 69-90.

Donner, W. 1996. "Inherent Value and Moral Standing in Environmental Change". In Hampson, F.0. \& Reppy, J. (Eds.). Earthly Goods: Environmental Change and Social Justice. Ithaca, New York: Cornell University Press. 
Elliot, R. 1997. Faking Nature: The Ethics of Environmental Restoration. London: Routledge.

Gardiner S.M. 2010. "A Perfect Moral Storm: Climate Change, Intergenerational Ethics, and the Problem of Moral Corruption". In Gardiner, S.M., Caney, S., Jamieson, D. \& Shue, H. (Eds.). Climate Ethics. Essential Readings. New York, NY: Oxford University Press.

Goodpaster, K. 2008. “On Being Morally Considerable”. In Pojman, L. \& Pojman, P. (Eds.), Environmental Ethics: Readings in Theory and Application. Belmont, California: Thomson Wadsworth.

Hargrove, E. 2003. "Weak Anthropocentric Intrinsic Value”. In Light, A. \&

Rolston III, H. (Eds.), Environmental Ethics: An Anthology. Malden, Massachusetts: Blackwell.

Lear, L. 1997. Rachel Carson: Witness for Nature. New York: Henry Holt and Company.

Leopold, A. 1987 [1949]. A Sand County Almanac: And Sketches Here and There. New York: Oxford University Press.

Light, A. \& Katz, E. (Eds.). 1996. Environmental Pragmatism. London: Routledge.

Light, A. \& Rolston III, H. (Eds.). 2003. Environmental Ethics: An Anthology.

Malden, Massachusetts: Blackwell.

McShane, K. 2009. "Why Environmental Ethics Shouldn't Give Up on Intrinsic Value". In Spash, C. (Ed), Ecological Economics. Critical Concepts in the Environment. London: Routledge.

Muir, J. 1991 [1916]. A Thousand-Mile Walk to the Gulf. San Francisco: Sierra Club Books.

Muir, J. 1988 [1912]. The Yosemite. San Francisco: Sierra Club Books.

Najder-Stefaniak, K. 2014. "Value of an Encounter from an Ethical Perspective". Ethics in Progress 5 (1): 115-124.

Norton, B. 2003. "Environmental Ethics and Weak Anthropocentrism". In Light, A. \& Rolston III, H. (Eds.), Environmental Ethics: An Anthology. Malden, Massachusetts: Blackwell.

O’Neill, J., Holland, A. \& Light, A. 2008. Environmental Values. London: Routledge.

O’Neill, J. 1993. Ecology, Policy and Politics. Human Well-Being and the Natural World. London: Routledge.

O’Neill, J. 2003. “The Varieties of Intrinsic Value”. In Light, A. \& Rolston III, H. (Eds.), Environmental Ethics: An Anthology. Malden, Massachusetts: Blackwell.

Paddock, T. 2014. "Building within space: Thoughts towards an Environmental Ethics". Ethics in Progress 5 (1): 81-97.

Pojman, L. \& Pojman, P. 2008. Environmental Ethics: Readings in Theory and Application. 5th ed. Belmont, California: Thomson Wadsworth.

Plumwood, V. 1993. "The Politics of Reason: Towards a Feminist Logic". Australasian Journal of Philosophy 71(4): 446-447. 
Proctor, J. D. 2001. "Solid Rock and Shifting Sands: The Moral Paradox of Saving a Socially-Constructed Nature". In Castree, N. \& Braun, B. (Eds.), Social Nature: Theory, Practice and Politics. Oxford: Blackwell.

Rachels, J. 2012. "Modern Ethical Theory: Introduction”. In Cahn, S. \& Markie, P. (Eds.). Ethics: History, Theory, and Contemporary Issues. New York: Oxford University Press: 451-460.

Robinson, J. 2004. "Squaring the Circle? Some Thoughts on the Idea of Sustainable Development". Ecological Economics. 48 (4): 369-384.

Rolston III, H. 2008. "Naturalizing Values: Organisms and Species”. In Pojman, L. \& Pojman, P. 2008. Environmental Ethics: Readings in Theory and Application. 5th ed. Belmont, California: Thomson Wadsworth.

Salwa, M. 2014. "Historic Gardens as Places of Conflicting Values". Ethics in Progress 5 (1): 98-114.

Söderbaum, P. 2008. Sustainability Economics. Towards Pluralism in Economics. London: Earthscan.

Sylvan (Routley), R. 2003. "Is there a Need for a New, an Environmental Ethic?" In Light, A. \& Rolston III, H. (Eds.), Environmental Ethics: An Anthology. Malden, Massachusetts: Blackwell.

Thoreau, H. D. 1993 [1862]. Walking. In Civil Disobedience and Other Essays. New York: Dover.

Tyburski, W. 1990. O idei humanizmu ekologicznego. Warsaw: Towarzystwo Wiedzy Powszechnej Zarząd Główny.

Vilkka, L. 1997. The Intrinsic Value of Nature. Amsterdam: Rodopi.

Zimmerman, M., Callicott, J. B. Sessions, G., Warren K. \& Clark, J. (Eds.). 1993. Environmental Philosophy: From Animal Rights to Radical Ecology. Englewood Cliffs, New Jersey: Prentice Hall. 
Małgorzata Dereniowska (Greqam, Aix-Marseille University)

Jason Matzke (University of Mary Washington)

\title{
Interdisciplinary Foundations for Environmental and Sustainability Ethics: An Introduction
}

\begin{abstract}
This article introduces the special issue for Ethics in Progress entitled Environment, ethics, and sustainability: Crossroads of our future. Despite four decades of intense development in the field of academic and professional environmental ethics, environmental problems pose ever increasing ethical challenges. The discipline continues to undergo a transition from focusing on theoretical questions such as what kinds of beings deserve moral standing toward greater inclusion of the multifaceted dimensions of sustainability and environmental issues and policy formation. In this introductory paper, we present the development, some of the key disciplinary debates, and the continuing and emerging challenges in environmentalism as it intersects with sustainability. We emphasize the importance of increasing the range of interdisciplinary perspectives brought to bear on practical ethics. The papers included in this special issue reflect both the challenges that arise as environmental ethics continues to expand and explore new issues at the intersection of ethics, sustainability, and environmental research, and the interdisciplinarity required in our search to better understand matters related to environmental history, environmental inequalities, social and environmental value conflict, inter-generational justice, and ethical components of the human relationship with the world.
\end{abstract}

Keywords: Environmental ethics, sustainability, intrinsic value of nature, interdisciplinarity

Ethics in Progress (ISSN 2084-9257). Vol. 5 (2014). No. 1. pp. 07-32.

doi:10.14746/eip.2014.1.1 